\title{
A Distribuição Espacial da Indústria no Sul do Brasil e sua Convergência
}

\section{The Spatial Distribution of Industry in Southern Brazil and lts Convergence}

\author{
Augusta Pelinski Raiher* \\ Jandir Ferrera de Lima* * \\ Cristiane Fernanda Klein***
}

Resumo: Este artigo analisa a distribuição espacial do setor secundário na região Sul do Brasil e sua convergência no período de 1985 a 2009. Para seu desenvolvimento, foram calculados indicadores de análise regional e estimados modelos econométricos usando dados em painel. Os resultados mostraram o aumento percentual de microrregiões especializadas na indústria na região Sul e uma distribuição espacial mais homogênea. Na análise quanto à convergência industrial, as condições iniciais e as características estruturais (escolaridade, população, PIB per capita) tornaram-se relevantes na determinação da participação no PIB industrial de cada região.

Palavras-chave: Economia regional. Crescimento econômico. Convergência industrial.

Abstract: This article analyzes the spatial distribution of the secondary sector in Southern Brazil and its convergence in the period from 1985 to 2009. For its development, were calculated analysis indicators and regional econometric models estimated using panel data. The results showed an increase in the percentage of micro specialized industry in the South and a more homogeneous spatial distribution. In the analysis regarding industrial convergence, the initial conditions and structural characteristics (education, population, GDP per capita) have become relevant in determining participation in industrial GDP of each region.

* $\quad$ Doutora em Economia do Desenvolvimento (UFRGS). Professora do Departamento de Ciências Econômicas da Universidade Estadual de Ponta Grossa (UEPG). E-mail: apelinski@gmail.com

** Ph.D. Desenvolvimento Regional pela Université du Québec (UQAC). Bolsista de produtividade do Conselho Nacional de Desenvolvimento Cientifico e Tecnológico (CNPQ) e Pesquisador do CNPQ e da Fundação Araucária (PR). Professor do Programa de Pós-Graduação em Desenvolvimento Regional e Agronegócio da Universidade Estadual do Oeste do Paraná (Unioeste). E-mail: jandir.lima@unioeste.br

*** Acadêmica do Colegiado de Ciências Econômicas da Unioeste. Bolsista de iniciação científica do CNPq. E-mail: cristiane_criss-@hotmail.com 
Keywords: Regional economy. Economic growth. Industrial convergence.

JEL Classification: O13; O25.

\section{1 lntrodução}

Este artigo analisa a distribuição espacial do setor secundário na região Sul do Brasil e sua convergência no período de 1985 a 2009. ${ }^{1}$

O setor secundário é o locus do dinamismo econômico de uma região, pois estimula e apresenta retornos crescentes de escala tanto internamente quanto em outros ramos produtivos. Além disso, há duas vias pelas quais o crescimento do setor secundário tende a elevar também a produtividade da economia como um todo: na primeira, a expansão da indústria eleva a demanda por mão de obra, ao mesmo tempo em que estimula o crescimento da produção e da produtividade fora da manufatura; na segunda via, a existência de rendimento crescente na indústria, tanto estático (tamanho e escala das unidades de produção) quanto dinâmico (rendimentos decorrentes do progresso tecnológico), contribui para esse dinamismo (KALDOR, 1989; THIRLWALL, 2005).

Empiricamente, Pieper (1998) aponta que países com um maior crescimento na indústria de transformação apresentam um crescimento maior da produtividade em todo o setor industrial. Feijó, Carvalho e Rodriguez (2003) encontraram resultados similares a Pieper (1998), apontando para a importância da indústria no processo de inovação e, consequentemente, no aumento da produtividade.

No caso brasileiro, ao longo do século XX, a distribuição espacial da indústria foi desigual, centrando-se principalmente no estado de São Paulo. A partir da década de 1970, até meados dos anos de 1980, ocorreu um processo de desconcentração regional das atividades produtivas, e umas das principais regiões beneficiárias desse processo foi a região Sul. Tanto que o Sul passou de $12 \%$ de participação industrial, em 1970, para 16,7\%, em 1985, e 18,1\%, em 1995. Acredita-se que essa reestruturação ocorreu por conta da desconcentração paulista, pelo esgotamento da fronteira agrícola, caracterizando uma produção mais intensa no seu espaço, nas décadas de 1980 e 1990, pelo crescimento urbano (CANO, 1997; IPEA, 2001; MARTINE; DINIZ, 1999; FERRERA DE LIMA et al., 2007; FERRERA DE LIMA, 2012).

No entanto, numa análise feita por Ferrera de Lima et al. (2007), verificou-se que entre os anos de 1970 e 1998 as atividades ligadas ao setor industrial e de serviços no Sul estavam mais concentradas nas mesorregiões metropolitanas, enquanto que as atividades ligadas à agropecuária estavam mais distribuídas entre

Esse texto é baseado em pesquisa financiada pelo Conselho Nacional de Desenvolvimento Cientifico e Tecnlógico (CNPQ) e pela Fundação Araucária (PR). 
as mesorregiões, em especial aquelas posicionadas na porção oeste da região Sul, em particular nas mesorregiões Oeste e Sudoeste paranaense, Oeste catarinense, Norte rio-grandense e na fronteira Oeste e Sudoeste rio-grandense. Ou seja, a distribuição espacial da indústria estava concentrada em áreas metropolitanas, ou seja, poucos pontos da região Sul, enquanto as atividades primárias estavam mais dispersas.

Considerando a importância que o setor secundário tem para o crescimento econômico e levando em conta que a sua distribuição, entre as décadas de 1970 e 1990, não se deu homogeneamente na região Sul, questiona-se: como foi a distribuição do setor secundário na região Sul do Brasil entre o final do século XX e o início do século XXI? Houve convergência na localização e distribuição espacial? Para responder a esses questionamentos, o procedimento metodológico utilizado foi a estimativa de indicador de análise regional e de painel. O período de análise foi de 1985 a 2009.

Para isso, este trabalho apresenta quatro seções, incluindo esta introdução. Na segunda têm-se os elementos teóricos e metodológicos que norteiam este estudo, na terceira apresenta-se a distribuição espacial da indústria no sul do país, na quarta tem-se a análise quanto à convergência e, para finalizar, têm-se as considerações finais.

\section{Elementos Teóricos e Metodológicos}

As disparidades regionais, em especial as econômicas, são o resultado direto do investimento e do crescimento de algumas atividades de transformação (referindo-se especialmente às indústrias motrizes), visto que a implantação de uma indústria não consegue atingir todo um país, por mais intenso que seja seus efeitos prospectivos. As regiões mais próximas das indústrias motrizes tendem a ser mais afetadas em termos de crescimento econômico e a ter mais condições de desenvolvimento que outras mais distantes (HIRSCHMAN, 1961).

A extensão dos efeitos é determinada tanto pela distância quanto pela capacidade de gerar externalidades positivas no entorno regional e, até mesmo, em outros espaços econômicos. A magnitude desses efeitos se dá tanto pelo consumo, ampliando o efeito multiplicador nas áreas de mercado da região, quanto pelos estímulos à acumulação de capital em outros ramos produtivos da economia. Ou seja, no processo de crescimento e desenvolvimento econômico regional, a desigualdade inter-regional torna-se inevitável. $\mathrm{O}$ avanço de uma região gera pressões, tensões, coações e relações de dependência entre as atividades produtivas e seu espaço e isso se transmite com diferentes intensidades para áreas subsequentes, em virtude da complementariedade existente entre as próprias atividades produtivas. 
Inicialmente, o crescimento e desenvolvimento econômico regional ocorre em alguns pontos do espaço e em determinadas unidades industriais. Apesar de desequilibrado, num segundo momento, esse processo se alastra para outros ramos industriais e para outras regiões por meio de todo um encadeamento e complementariedade existente. Além disso, o processo de crescimento e desenvolvimento econômico estimula a criação de infraestrutura diferenciada em alguns núcleos, atraindo investimentos para o setor produtivo, fortalecendo o desenvolvimento somente naquele polo. Por isso, a indústria motriz tem um papel determinante, com poder de ampliar os efeitos do encadeamento em direção às atividades polarizadas. Num segundo momento, esse crescimento concentrado é difundido, por canais, como os meios de transportes e comunicação, e através dos insumos industriais, do comércio de bens finais e das matérias-primas (HIRSCHMAN, 1961; PERROUX, 1974).

A indústria motriz é peça-chave para dinamizar as economias regionais, estimulando tanto os encadeamentos quanto a atração de outras atividades, principalmente aqueles do setor terciário. Ou seja, ela estimula as aglomerações e amplia a área de influência (ANDRADE, 1987).

Nas abordagens do crescimento e desenvolvimento desiquilibrado, a expectativa é que no longo prazo o desenvolvimento se torne mais homogêneo no espaço, com a hipótese de que haja fortes efeitos de encadeamento das atividades produtivas.

A homogeneização ou convergência da localização de indústria no Sul do Brasil torna-se, então, elemento importante sobre o grau de avanço ou retardo das economias regionais. Por isso, este estudo tem como objeto a especialização industrial de cada microrregião do Sul do Brasil, com análise para os anos de 1985, 1996, 2000, 2005 e 2009. Os resultados fornecerão um quadro de informações sobre alterações significativas com a homogeneização da atividade de transformação ao longo do espaço regional. A variável utilizada foi o PIB a preços de mercado setorial deflacionado para 2000. A fonte dos dados foi o Instituto de Pesquisa Econômica Aplicada (Ipea), por meio de sua base de dados, o Ipeadata.

Para a análise, foi estimado o Quociente Locacional (QL), que na análise regional é utilizado como medida de localização (conforme a equação 01). O QL também indica especialização, pois compara a participação percentual da variável-chave, no caso o PIB, em uma determinada região com a participação percentual da região de referência. Assim, fornece indicadores de importância do setor entre as regiões.

$$
Q L=\left(S_{i} / S_{t}\right) /\left(\mathrm{N}_{i} / \mathrm{N}_{t}\right)
$$


Em que: QL refere-se ao quociente locacional; $S_{i}$ é o PIB setorial na atividade i na microrregião; $S_{t}$ é o PIB total na microrregião; $N_{i}$ refere-se ao PIB setorial na atividade i no Sul do Brasil; $N_{t}$ é o PIB total no Sul do Brasil.

$\mathrm{Na}$ análise do $\mathrm{QL}$, assumindo valores superiores à unidade (superiores a 1) a região se mostra significativa no setor ou ramo de atividade e este, então, será considerado especializado ou com localização significativa. Caso o resultado do QL seja inferior à unidade, o setor não é significativo na região. Ou seja, esse indicador apresenta o comportamento locacional dos ramos de atividades, apontando quais os setores com localização significativa e, consequentemente, mais especializados nas diferentes regiões.

Após essa análise, a hipótese de convergência industrial foi testada por meio de estimativas econométricas, com dados em painel. É importante destacar que há vários conceitos acerca da convergência. Um desses refere-se ao $\beta$-convergência, que identifica a ocorrência de convergência quando regiões mais pobres, ou com uma estrutura produtiva menos desenvolvida, crescem mais rápido que as regiões ricas.

Em uma regressão de cross-section, na qual a taxa de crescimento da renda é a variável dependente, a $\beta$-convergência está presente quando se obtém um coeficiente negativo para o nível inicial da renda per capita. Como o foco é analisar a convergência industrial, e como o crescimento da participação no PIB industrial é uma variável dependente, se o coeficiente para o nível inicial da participação for negativo, tem-se a presença do $\beta$-convergência para a região.

Ressalta-se que na abordagem do $\beta$-convergência há três hipóteses:

a) convergência absoluta, condicional e de clubes de convergência: neste caso, as rendas per capita das regióes convergem para um único estado estacionário, independentemente de suas condições iniciais;

b) convergência condicional: neste caso, a renda per capita das regiões, que são idênticas nas suas características estruturais, convergem, no longo prazo, independentemente da sua condição inicial; no entanto, como existem diferenças estruturais entre as regiões, estas convergem para diferentes estados estacionários;

c) clubes de convergência: quando as rendas per capita das regiões com características estruturais idênticas convergem no longo prazo somente quando suas condições iniciais são muito próximas, existindo múltiplos equilíbrios estáveis.

Para testar e verificar essas hipóteses, estimou-se a equação 2, obtendo, assim, a estimativa quanto à convergência absoluta. A variável dependente utilizada foi o crescimento da participação no PIB industrial das microrregiões do Sul do Brasil e a explicativa foi o logaritmo da participação inicial no PIB industrial. O mé- 
todo de estimação foi o de painel, considerando o período de 1985 a 2009, com dados quinquenais. ${ }^{2}$

$$
\frac{1}{T} \ln \left(\frac{Y_{i t}}{Y_{i, 0}}\right)=\beta_{1}+\beta_{2} \ln \left(Y_{i, 0}\right)+u_{i}
$$

Na equação 2, $T$ refere-se ao intervalo de tempo; $Y$ é a participação no PIB industrial; 0 refere-se ao período inicial; $t$ é o período final; $i$ representa a i-ésima unidade de corte transversal (microrregião do Sul do Brasil).

Cabe ressaltar que ao se usar dados em painel deve-se decidir-se entre estimação por efeito fixo (EF) ou por aleatório (EA). Na estimação por EF, assume-se que as diferenças entre as unidades de análise são mudanças paramétricas da função de produção. Já no método de estimação via EA, tem-se como suposição que a especificidade de cada unidade de análise é distribuída de forma aleatória. A principal motivação para a utilização da técnica de dados em painel foi a possibilidade do controle do componente não observável (C). Caso este não seja correlacionado com as variáveis explicativas do modelo, o modelo de EA fornece estimativas consistentes dos parâmetros. Porém, se o componente $\mathrm{C}$ estiver correlacionado com as variáveis explicativas da equação, esse modelo será inconsistente. Nessa situação, para se obter estimativas consistentes dos parâmetros, deve-se utilizar o modelo EF (WOOLDRIDGE, 2002).

O teste utilizado para decidir entre EA e EF é o teste de Hausman, optando pelo método $\mathrm{EF}$, dado que se rejeitou a hipótese nula (conforme os resultados no Apêndice B).

Por fim, fizeram-se os testes de heterocedasticidade (Breusch-Pagan) e autocorrelação (via o teste desenvolvido por Woodridge, 2002), identificando problemas de heterocedasticidade e de autocorrelação (resultados apresentado no Apêndice B). A solução foi estimar por Feasible Generalizad Least Squares (FGLS). No entanto, como se está estimando por efeitos fixos, para usar FGLS foi necessário introduzir variáveis dicotômicas para as unidades espaciais. O passo inicial foi a criação de dummies para cada uma das unidades (microrregião) rodando por FGLS, corrigindo, assim, os problemas de heterocedasticidade e autocorrelação, via o software Stata.

No caso da convergência condicional, esta foi estimada por meio da equação 03, via a metodologia de dados em painel, tendo como variáveis explicativas: força de trabalho (POP), mensurada pelo tamanho da população; escolaridade

$2 \quad$ Destaca-se que a participação inicial no PIB iniciou com dados de 1985 e o crescimento da participação começou com a taxa de 1985 para 1996. Não se usou de 1985 para 1990 pela indisponibilidade de dados. 
média (Esc) de cada microrregião, considerando apenas a população com trabalho formal, como medida de produtividade; PIB per capita (PIBper), como proxy para o padrão de consumo industrial; e logaritmo da participação inicial no PIB industrial. ${ }^{3}$

$$
\frac{1}{T} \ln \left(\frac{Y_{i t}}{Y_{i, 0}}\right)=\beta_{1}+\beta_{2} 1 n\left(Y_{i, 0}\right)+\beta_{3} E s c+\beta_{4} \text { PIBper }+\beta_{5} \text { PIBper }^{2}+\beta_{6} P O P+u_{i}
$$

Destaca-se que, para o PIB per capita, considerando a Lei de Engel - a qual relaciona inicialmente um aumento do consumo de bens industrializados à elevação da renda per capita, e a partir de certo nível desta o consumo passa a crescer mais lentamente -, usou-se a forma funcional quadrática. A expectativa é uma contribuição positiva do PIB per capita e uma contribuição negativa do PIB per capita ao quadrado na determinação da participação do PIB industrial de cada microrregião do Sul (CARATORI, 2011).

Por se estar utilizando a metodologia de dados em painel, novamente fez-se o teste de Hausman para se decidir entre EF e EA. Optando-se pelo primeiro dado, se rejeitou a hipótese nula (Apêndice B). Por fim, fizeram-se os testes de heterocedasticidade (Breusch-Pagan) e autocorrelação (via o teste desenvolvido por Woodridge), identificando novamente os problemas de heterocedasticidade e de autocorrelação (resultados apresentados no Apêndice B). Por isso, também foi estimado por FGLS, com a metodologia de EF, visando corrigir tais problemas econométricos.

A última análise feita foi quanto à existência de clubes de convergência no Sul do Brasil, identificando se as microrregiões com condições iniciais muito próximas convergem (em termos de participação no PIB industrial) no longo prazo. Para isso, primeiramente as microrregiões foram classificadas em três grupos, por meio da análise de clusters, conforme identificados no dendograma do Apêndice A. Tal classificação levou em conta as características quanto à escolaridade, PIB per capita e população - todos dados de 1995 -, além da participação no PIB industrial de 1985. No Quadro 1 são apresentadas as microrregiões pertencentes a cada grupo.

\footnotetext{
Utilizando variáveis sugeridas por Caratori (2011).
} 
Quadro 1 - Clusters das microrregiões do Sul do Brasil (1985-2009)

\begin{tabular}{|c|c|c|c|}
\hline Clube 1 & Clube 2 & \multicolumn{2}{|c|}{ Clube 3} \\
\hline $\begin{array}{c}\text { Curitiba } \\
\text { Porto Alegre }\end{array}$ & $\begin{array}{c}\text { Apucarana } \\
\text { Cascavel } \\
\text { Francisco Beltrão } \\
\text { Londrina } \\
\text { Maringá } \\
\text { Ponta Grossa } \\
\text { Toledo } \\
\text { Campanha Ocidental } \\
\text { Caxias do Sul } \\
\text { Gramado-Canela } \\
\text { Lajeado-Estrela } \\
\text { Montenegro } \\
\text { Santa Cruz do Sul } \\
\text { São Jerônimo } \\
\text { Blumenau } \\
\text { Campos de Lages } \\
\text { Chapecó } \\
\text { Concórdia } \\
\text { Criciúma } \\
\text { Florianópolis } \\
\text { Itajaí } \\
\text { Joaçaba } \\
\text { Joinville } \\
\text { São Bento do Sul } \\
\text { Tubarão } \\
\text { Xanxerê }\end{array}$ & $\begin{array}{c}\text { Astorga } \\
\text { Campo Mourão } \\
\text { Capanema } \\
\text { Cerro Azul } \\
\text { Cianorte } \\
\text { Cornélio Procópio } \\
\text { Faxinal } \\
\text { Floraí } \\
\text { Foz do Iguaçu } \\
\text { Goioerê } \\
\text { Guarapuava } \\
\text { Ibaiti } \\
\text { Irati } \\
\text { Ivaiporã } \\
\text { Jacarezinho } \\
\text { Jaguariaíva } \\
\text { Lapa } \\
\text { Palmas } \\
\text { Paranaguá } \\
\text { Paranavaí } \\
\text { Pato Branco } \\
\text { Pitanga } \\
\text { Porecatu } \\
\text { Prudentópolis } \\
\text { Rio Negro } \\
\text { São Mateus do Sul } \\
\text { Umuarama Borba } \\
\text { União da Vitória } \\
\text { Wenceslau Braz } \\
\text { Cachoeira do Sul } \\
\text { Camaquã }\end{array}$ & 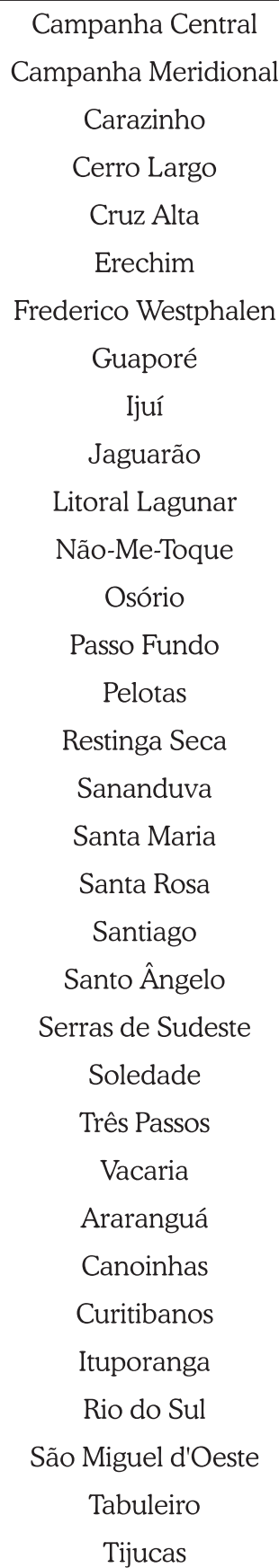 \\
\hline
\end{tabular}

Fonte: Elaboração própria a partir do software SPSS. 
Como Curitiba e Porto Alegre foram as únicas cidades que compunham o cluster um, na análise de regressão não foi considerado tal grupo, a fim de evitar problemas econométricos. Para analisar se ocorreu convergência em clube no Sul do Brasil, em termos de convergência condicional, estimou-se por meio da equação 4. Isso foi necessário porque os resultados demonstraram (seção 4.2) que a hipótese condicional é mais forte que a absoluta, seguindo a metodologia aplicada por Bertussi e Figueiredo (2009). A seguir apresenta-se a equação 4:

$$
\frac{1}{T} \ln \left(\frac{Y_{i t}}{Y_{i, 0}}\right)=\sum_{j=1}^{2} B_{0 j} D_{i j}+\left(\sum_{j=1}^{2} B_{1 j} D_{i j}\right) \operatorname{Ln}\left(\mathrm{Y}_{i 0}\right)+\left(\sum_{j=1}^{2} B_{2 j} D_{i j}\right) Z_{i t}+u_{t}+\varepsilon_{i t}
$$

Em que: $D$, se a microrregião $i$ pertencer ao clube j, para $j=1,2 . Z_{i t}$, refere-se ao conjunto de variáveis de controle (escolaridade, população, PIB per capita) da microrregião i no período $t$.

Ao se estimar a equação 4, cada um dos clubes é descrito por um modelo linear distinto. Tal estimativa foi feita via metodologia de dados em painel, usando a abordagem de feitos fixos (valor do teste de Hausman foi igual a 24, significativo a 5\%). Da mesma forma que nas regressões estimadas pelas equações 1 e 2, a regressão da equação 3 também apresentou problemas de heterocedasticidade e de autocorrelação serial (ver Apêndice B), e por isso foi estimado por FGLS.

\section{Perfil Locacional do PIB na Região Sul do Brasil}

No processo de desenvolvimento econômico da região Sul do Brasil, até os anos 1970 os seus níveis de produtividade industrial eram baixos. Já entre 1970 até os anos de 1990, o crescimento foi mais significativo, com aproximação da média nacional.

Houve três aspectos que estimularam esse crescimento no Rio Grande do Sul: a expansão agrícola e seus efeitos de encadeamento nas cadeias agroindustriais; o crescimento das indústrias de bens de capital e de consumo duráveis no eixo região metropolitana de Porto Alegre-Caxias do Sul; e o crescimento da indústria de couro e calçados. No caso de Santa Catarina, esta foi beneficiada por uma dupla base industrial, tanto de indústrias tradicionais (alimentos, têxteis, cerâmica, extração vegetal) quanto de maior conteúdo tecnológico (metal mecânica, mecatrônica, petroquímica), ambas dispersas no espaço regional. Já o estado do Paraná teve grande expansão das agroindústrias processadoras de proteína animal e vegetal, devido à qualidade das terras e da expansão da produção agrícola (KLEINSCHMITT; FERRERA DE LIMA, 2011).

No entanto, ao se analisar a especialização das microrregiões da região Sul em 1985 (Figura 1), verifica-se a concentração industrial em alguns pontos, abrangendo apenas $26 \%$ das microrregiões. Assim, por mais que a região Sul tenha ga- 
nhado em dinamismo no processo produtivo industrial, este não foi homogêneo em sua totalidade.

Analisando por estado, $45 \%$ das microrregiões de Santa Catarina eram especializadas na produção do setor secundário, contra apenas 21\% do Paraná e 20\% do Rio Grande do Sul. Ou seja, Santa Catarina detinha, em 1985, uma homogeneização maior quanto à distribuição industrial no seu espaço regional, estando de acordo com os apontamentos de Souza e Ferrera de Lima (2010) e Kleinschmitt e Ferrera de Lima (2011).

Na Figura 1, na ilustração a, se percebe a formação de dois corredores compostos por microrregiões especializadas no setor secundário em 1985. Um ligava Criciúma e Tubarão, Sudeste de Santa Catarina, a Palmas e União da Vitória, Sul do Paraná. O outro ligava Itajaí e Blumenau, Nordeste de Santa Catarina, a Apucarana, Norte do Paraná. Além desses dois corredores, na porção Leste do Rio Grande do Sul se localizava um aglomerado de microrregióes especializadas no setor secundário, formando um arquipélago industrial com o entorno agrário. 
Figura 1 - QL do PIB do setor secundário das microrregiões da região Sul:

a) 1985 ; b) 1996 ; c) 2000 ; d) 2005 ; e) 2009

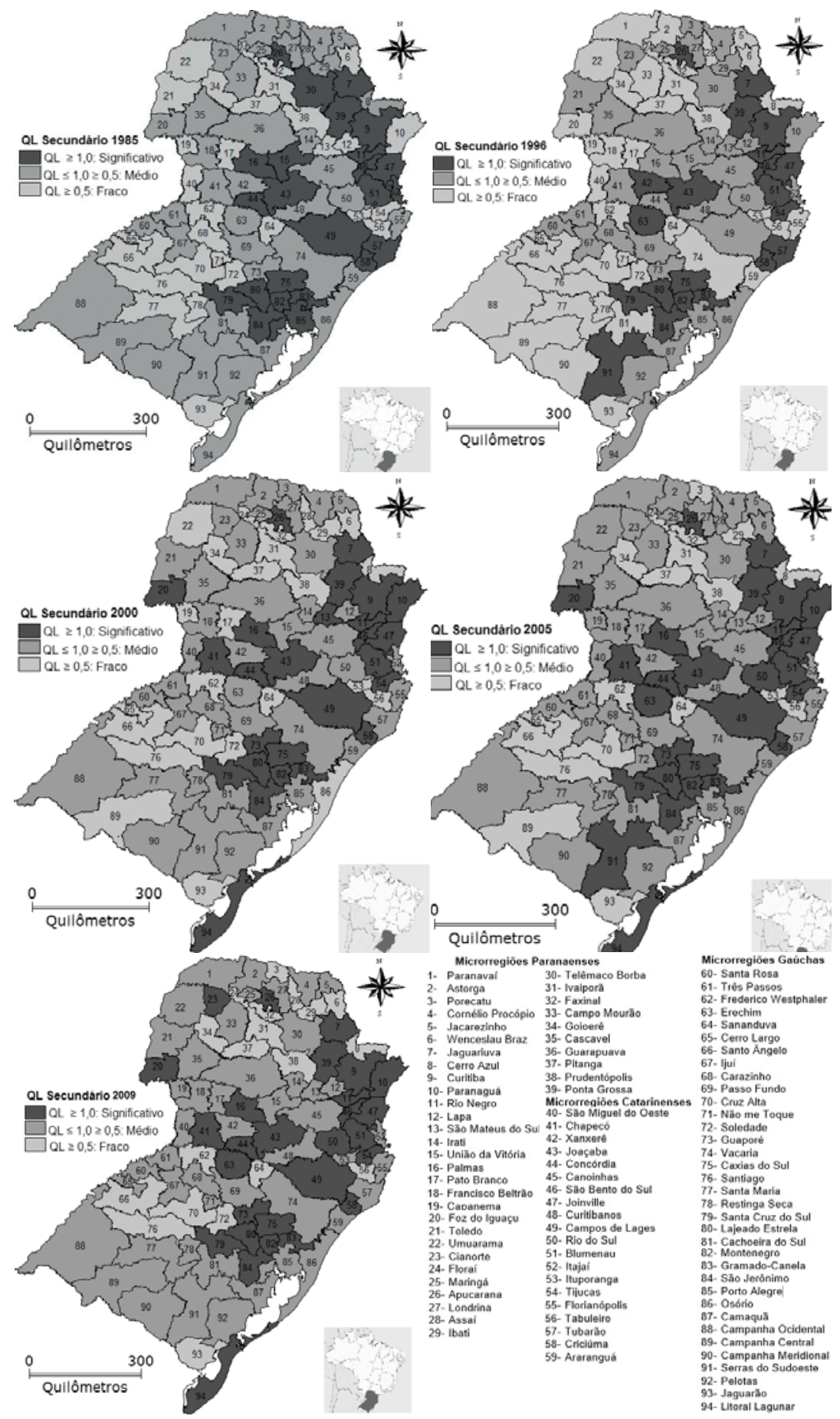

Fonte: Elaboração própria a partir de dados do Ipeadata (2012). 
A expectativa, pela teoria do crescimento desequilibrado, seria de que, com o decorrer do tempo e a ação de externalidades positivas ao longo do território, o crescimento econômico e industrial fosse difundido em direção às regiões mais periféricas, tornando as microrregiões mais homogêneas na sua composição setorial. No entanto, de 1985 para 1996, apenas o Rio Grande do Sul aumentou o percentual de microrregiões especializadas no setor secundário, passando de $20 \%$ para 23\%. Em Santa Catarina ocorreu o contrário, pois o percentual de microrregiões especializadas na transformação industrial caiu de $45 \%$ para $40 \%$, e o Paraná, com a maior perda, passou para apenas $13 \%$ das suas microrregiões. Não foram apenas as microrregiões especializadas no setor secundário que tiveram retração, mas também aquelas nas quais havia um QL intermediário (entre 0,5 e 1). Elas representavam $43 \%$ de todas as microrregiões, em 1985, e ficaram em apenas $36 \%$ em 1996.

Cabe esclarecer que ao longo do processo de desenvolvimento econômico, Singer (1971) e Ferrera de Lima (2010) afirmam que o setor primário aparece como responsável pela dinâmica das atividades urbanas (secundárias e terciárias). O setor primário gera um montante de produção e recursos financeiros que sustenta o comércio, a prestação de serviços e as atividades de transformação por vezes incipiente. Ao longo do tempo, com o avanço no grau e estágio de desenvolvimento, cada vez mais as atividades urbanas ganham importância, principalmente quando formam uma base econômica significativa, e, com isso, o setor primário perde importância na geração de empregos e na agregação de valor. É a chamada transição do continuum urbano-rural para o continuum urbano-industrial.

Segundo Cano (1997, p. 118-119), de 1985 até 1994 ocorreu a inflexão no processo de desconcentração industrial brasileiro, pois o crescimento econômico do Brasil e de São Paulo foi "medíocre", resultando numa inibição do crescimento das regiões periféricas do Brasil. As principais causas dessa inibição foram: o desmantelamento do Estado Nacional e seus órgãos regionais, implicado na ausência de políticas de desenvolvimento regional; a abertura do comércio exterior; a ausência de grandes investimentos na periferia; a debilidade fiscal e financeira do governo federal e estadual, causando acentuada queda nos investimentos de infraestrutura e de energia; a diminuição dos preços reais das commodities, contendo o crescimento do valor das exportações; a retração do ritmo de crescimento das exportações de manufaturados de indústrias tradicionais e de tecnologia madura, entre outros fatores.

Diniz (1995) reforça argumentando que na economia brasileira as transformações regionais da indústria se fazem fundamentalmente em função da orientação locacional dos novos investimentos, e não pela relocalização de unidades já existentes, e que, por isso, a crise que afetou o país na década de 1980 e no início de 1990 freou as alterações regionais da produção. Além disso, as transformações 
tecnológicas e estruturais em curso pareciam dificultar o processo de desconcentração macroespacial, reconcentrando as atividades modernas nas áreas mais desenvolvidas do país.

Os dados do emprego industrial da região Sul (Gráfico 1) demonstram que mesmo nesse período houve crescimento do emprego industrial na região como um todo. Assim, com exceção do Rio Grande do Sul, a região continuou a apresentar um dinamismo do seu setor secundário, concentrando, porém, essas atividades ainda mais em alguns pontos, afetada, possivelmente, pelo ambiente macroeconômico que o país vivenciava na época (crise da dívida, abertura comercial, etc.).

Gráfico 1 - Emprego do setor industrial da região Sul (1985, 1996, 2000, 2005 e 2009)

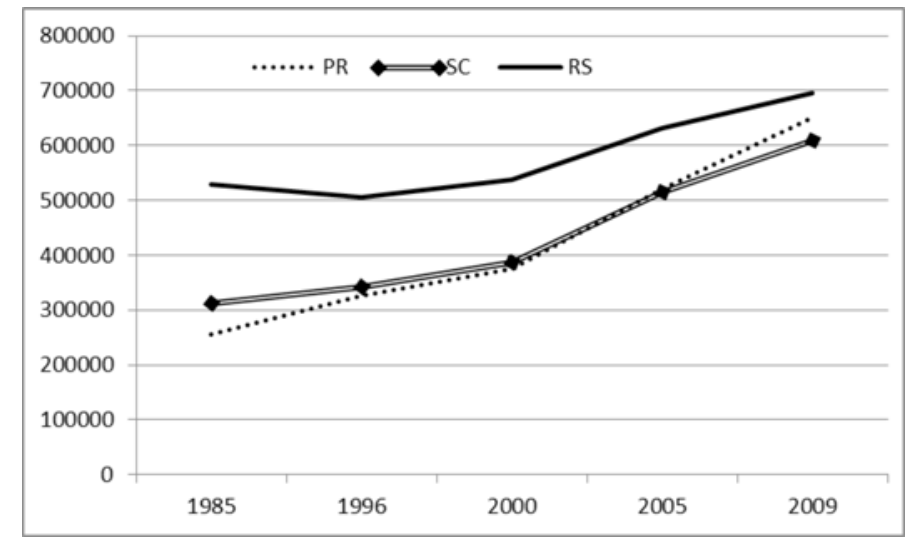

Fonte: Ipeadata (2012).

No ano de 2000 percebe-se, pela Figura 1, ilustração c, a melhora quanto à distribuição espacial das indústrias, elevando o percentual de microrregiões especializadas, sendo para 45\%, em Santa Catarina, para 23\%, no Paraná, e para 23\% no Rio Grande. Para Firkowski (1999) e Ferrera de Lima (2012), a partir de meados dos anos de 1990 a base territorial passivel de receber novos investimentos industriais se ampliou consideravelmente no Brasil. Esse movimento se insere no contexto da abertura comercial e financeira de privatizações, desregulamentações do mercado, incentivos governamentais e concessão de infraestrutura, ações que visavam o projeto de industrialização de cada região, operando em conjunto com uma maior autonomia fiscal dos estados federados.

Além de um maior número de microrregiões apresentar um QL superior à unidade, a sua distribuição espacial se assemelhava muito com a de 1985, com poucas alterações, consolidando os dois corredores e o aglomerado identificado em 1985.

Em 2005 (ver Figura 1, ilustração d) o Paraná foi o único que diminuiu o percentual de microrregiões especializadas no setor secundário, caindo para $21 \%$, ao contrário do Rio Grande do Sul - que deu um grande salto, passando a ter 29\% 
das suas microrregiões especializadas - e de Santa Catarina, com 50\%. A grande mudança foi a distribuição espacial, que deixou de estar concentrada nos dois corredores e no aglomerado, cobrindo de forma mais homogênea a região como um todo.

Por fim, no último ano de análise, 2009, o Paraná retomou o percentual de microrregiões de 2000, com 23\%; Santa Catarina permaneceu com o valor em torno de 50\%; e o Rio Grande caiu para 26\%. Ao se comparar os percentuais de 1985 com os de 2009, todos os estados melhoraram sua posição: o Rio Grande do Sul teve uma taxa de crescimento de $30 \%$ desse percentual, Santa Catarina de $11 \%$ e o Paraná de 10\%. Além disso, muitas das microrregiões que tinham um QL abaixo de 0,5 passaram a ter um valor médio, melhorando sua posição locacional, indicando um avanço quanto ao potencial de especialização produtiva da região: o Paraná tinha $44 \%$ das suas microrregiões com um QL médio, em 1985, e passou a 49\% em 2009; o Rio Grande do Sul tinha $46 \%$ e chegou a 54\% em 2009; e Santa Catarina tinha $35 \%$ e ficou com $45 \%$ em 2009.

No caso de Santa Catarina, a distribuição espacial das microrregiões especializadas ficou mais homogênea, não se concentrando apenas no corredor, mas se espraiando ao longo do espaço territorial do estado. Isso é importante frente aos postulados da teoria do crescimento desequilibrado, porque a expansão industrial, a princípio concentrada, se difundiu ex post para regiões mais contiguas às áreas industriais, gerando crescimento industrial e econômico num espaço regional mais amplo.

\section{Convergência Industrial na Região Sul do Brasil}

Os resultados apresentados acerca do melhoramento quanto à localização e distribuição de microrregiões especializadas no setor secundário no Sul do Brasil já é indicativo quanto a convergência industrial na região. A comprovação efetiva disso foi feita considerando três possibilidades: as convergências absoluta, condicional e em clube.

\subsection{Convergência Absoluta}

Nesta hipótese, a renda per capita (ou o processo produtivo) das regiões tende a convergir no longo prazo independentemente da sua condição inicial. Isso implica uma relação negativa entre a taxa de crescimento da participação do PIB industrial e o seu nível inicial. Considerando a abordagem neoclássica, o resultado de convergência se deve à hipótese de concavidade da função de produção e a condições sobre o comportamento da produtividade marginal quando o estoque de capital cresce indefinidamente ou tende a zero (PINHEIRO, 2001). A conver- 
gência se constata quando as regiões com menor participação inicial crescem mais rápido do que as regiões já inseridas no processo produtivo.

Os resultados apresentados na Tabela 1 indicam que na região Sul se processou o fenômeno de convergência, pois o sinal negativo para o coeficiente associado ao logaritmo da participação inicial do PIB industrial é interpretado como evidência de convergência absoluta (BARRO; SALA-I-MARTIN, 1995). Ou seja, a participação no PIB industrial observada nas microrregiões nas quais era menor cresceu mais do que nas microrregiões nas quais era maior, indicando que está convergindo para um estado estacionário, independente das condições iniciais. $\mathrm{O}$ valor do parâmetro indica que a velocidade de convergência no Sul é em torno de $14 \%$ ao ano.

Como a comparação da Figura 1, ilustrações $a$ e $e$, indica que a melhora que se teve quanto à participação das microrregiões no setor secundários não foi igual entre os estados da região, então se fez estimativas individuais. Como corolário, todos apresentaram um parâmetro negativo para a participação inicial, no entanto, em Santa Catarina, estado no qual se apresentou uma homogeneização maior quanto à distribuição espacial das industriais, a magnitude da convergência é maior do que nos demais.

Tabela 1 - Convergência absoluta das microrregiões do Sul do Brasil (1985-2009): efeitos fixos (variável dependente: taxa de crescimento da participação no PIB industrial)

\begin{tabular}{ccc}
\hline Região/Estado & Constante & Ln da participação inicial no PIB industrial \\
\hline \multirow{2}{*}{ Região Sul } & $-0,025$ & $-0,1999$ \\
& $(0,006)^{*}$ & $(0.005)^{*}$ \\
Paraná & $-0,025$ & $-0,201$ \\
& $(0,005)^{*}$ & $(0,007)^{*}$ \\
Rio Grande do Sul & $-0,28$ & $-0,195$ \\
Santa Catarina & $(0,024)^{*}$ & $(0,011)^{*}$ \\
\hline Fonte: Elo, & $-0,24$ & $-0,21)^{*}$ \\
\hline
\end{tabular}

Fonte: Elaboração própria a partir dos resultados da pesquisa.

Nota: *Rejeita-se $\mathrm{H}_{0}$ a um nível de $5 \%$ (teste t). Entre parênteses, refere-se ao desvio padrão do estimador. Ln refere-se ao logaritmo.

\subsection{Convergência Condicional}

Alguns autores criticam o modelo de convergência absoluta por se basear na hipótese de que todas as regiões apresentam padrões de preferências e níveis de tecnologia comuns (SOUZA; PORTO JÚNIOR, 2002). Com efeito, quando as características estruturais diferem entre regiões, o crescimento industrial de cada uma tende a convergir para seu próprio nível do estado estacionário e não para um nível comum, sendo esse tipo de convergência chamada de $\beta$-convergência condicional.

Admitindo que as conclusões do $\beta$-convergência absoluta são fracas (principalmente pela omissão de variáveis nas regressões da Tabela 1), novas estimativas 
foram realizadas utilizando-se a convergência-condicional. Para isso, acrescentou-se nas regressões da Tabela 1 um conjunto de variáveis explicativas (variáveis de controle). Com a inclusão desse grupo de variáveis continuou a se ter um coeficiente estimado da participação inicial no PIB industrial negativo e estatisticamente diferente de zero para a região Sul (Tabela 2). Houve também um processo de convergência do processo produtivo mais dinâmico, dado que em valor absoluto o coeficiente estimado é superior ao coeficiente obtido na regressão de convergência absoluta, com velocidade de convergência aumentando para $15 \%$ ao ano.

Com relação às variáveis de controle, todas exerceram efeito a um nível de significância de $5 \%$, sobre a taxa de crescimento da participação no PIB industrial do Sul. A variável escolaridade, proxy para a produtividade, indicou que um ano a mais de estudo da população tende a elevar a participação da microrregião no PIB industrial em $0,01 \%$. Para a população, o seu sinal positivo inferiu a existência de vantagens para as áreas com um nível populacional maior, sinalizando que o setor manufatureiro existente no Sul é mais sensível à escala. Por fim, o PIB per capita, variável proxy do padrão de consumo interno, com a forma funcional quadrática, indicou um efeito positivo da renda sobre o crescimento da participação da microrregião no PIB industrial, exercendo esse efeito até determinado ponto, a partir do qual o consumo de bens industrializados passou a crescer mais lentamente.

O fato do coeficiente da participação industrial inicial ser significativo e superior em valores absolutos na equação de convergência condicional, associado à relevância estatística e teórica das variáveis de controle, demonstrou a superioridade da hipótese de convergência condicional sobre a hipótese de convergência absoluta, melhor caracterizando o crescimento industrial da região Sul. Isso significa que as microrregiões da região, com características estruturais semelhantes, tendem a convergir para o mesmo padrão produtivo no longo prazo.

Como cada estado apresentou um padrão de distribuição das suas microrregiões especializadas (ver Figura 1, ilustração $e$ ), se estimou uma regressão para cada estado, apresentando os resultados na Tabela 2. Visualiza-se uma semelhança nos valores de convergência, pois todos apresentaram sinal negativo para a participação inicial na indústria. Isso comprova a convergência condicional, visto que as variáveis de controle foram significativas e com o sinal esperado pela teoria econômica. Além do coeficiente da participação inicial no PIB industrial ter vindo com sinal negativo para os três estados, veio numa magnitude maior do que a obtida na convergência absoluta, o que reafirma a superioridade da hipótese de convergência condicional para os estados do Sul. Ou seja, as microrregiões com características estruturais semelhantes tendem a convergir para um mesmo estado de desenvolvimento industrial. 
Tabela 2 - Convergência condicional das microrregiões do Sul do Brasil (1985-2009): efeitos fixos (variável dependente: taxa de crescimento da participação no PIB industrial)

\begin{tabular}{ccccccc}
\hline $\begin{array}{c}\text { Região/ } \\
\text { Estado }\end{array}$ & Constante & $\begin{array}{c}\text { Ln participação } \\
\text { inicial no PIB } \\
\text { Industrial }\end{array}$ & Escolaridade & PIB per capita & $\begin{array}{c}\text { PIB per capita } \\
\text { ao quadrado }\end{array}$ & População \\
\hline $\begin{array}{c}\text { Região } \\
\text { Sul }\end{array}$ & $-0,302$ & $-0,229$ & 0,008 & 0,00004 & $-8,17 \mathrm{e}-10$ & $5,63 \mathrm{e}-08$ \\
& $(0,17) 8$ & $(0,005)^{*}$ & $(0,001)^{*}$ & $(1,9 \mathrm{e}-08)^{*}$ & $(6,4 \mathrm{e}-11$ & $(1,9 \mathrm{e}-08)^{*}$ \\
PR & $-0,311$ & $-0,226$ & 0,007 & 0,00004 & $-4,15 \mathrm{e}-10$ & $5,92 \mathrm{e}-09$ \\
& $(0,34)^{*}$ & $(0,007)^{*}$ & $(0,003)^{*}$ & $(9,5 \mathrm{e}-06)^{*}$ & $(9,5 \mathrm{e}-06)^{*}$ & $(2,3 \mathrm{e}-08)^{*}$ \\
RS & $-0,595$ & $-0,241$ & 0,01 & 0,00004 & $-7,79 \mathrm{e}-10$ & $1,66 \mathrm{e}-07$ \\
& $(0,0295)^{*}$ & $(0,008)^{*}$ & $(0,001)^{*}$ & $(2,9 \mathrm{e}-06)^{*}$ & $(7.88 \mathrm{e}-11)^{*}$ & $(4,2 \mathrm{e}-08)^{*}$ \\
SC & $-0,489$ & $-0,239$ & 0,005 & 0,00004 & $-7,51 \mathrm{e}-10$ & $2,01 \mathrm{e}-07$ \\
& $(0,03)^{*}$ & $(0,008)^{*}$ & $(0,001)^{*}$ & $(3,2 \mathrm{e}-06)^{*}$ & $(1,0 \mathrm{e}-10)^{*}$ & $(4,9 \mathrm{e}-08)^{*}$ \\
\hline
\end{tabular}

Fonte: Elaboração própria a partir dos resultados da pesquisa.

Nota: *Rejeita-se $\mathrm{H}_{0}$ a um nível de $5 \%$ (teste t). Entre parênteses, refere-se ao desvio padrão do estimador. Ln refere-se ao logaritmo.

\subsection{Clube de Convergência}

Há uma última possibilidade de convergência quanto à estrutura industrial que pode estar ocorrendo no Sul, que é a convergência em clube. Nessa hipótese, as desigualdades do crescimento quanto à participação no PIB industrial existente entre as microrregiões estaria refletindo regiões que se situam em base de atração distintas, definidas pelas condições iniciais. Dentro dessa hipótese, têm-se dois cenários: clube de convergência no âmbito da convergência absoluta e clube de convergência no âmbito da convergência condicional. Como os resultados anteriores demonstraram uma superioridade da convergência condicional para os estados do Sul, então apenas esta foi testada dentro da hipótese de clube de convergência.

A hierarquização realizada (ver Apêndice A), na qual se considerou as condições iniciais de cada microrregião, identificou a existência de três grupos. Como no primeiro grupo apenas duas microrregiões faziam parte (Curitiba e Porto alegre), para evitar problemas econométricos optou-se por deixar de fora tais microrregiões. Assim, usando a equação 03, obteve-se os resultados da Tabela 3.

As estimativas em geral foram melhores que todas as anteriores, com coeficientes significativos e negativos para a participação inicial no PIB industrial, além destes serem, em valores absolutos, maiores ou próximos dos obtidos anteriormente, indicando uma taxa anual de convergência maior (Tabela 3). 
Tabela 3 - Clube de convergência condicional das microrregiões do Sul do Brasil (1985-2009): efeitos fixos

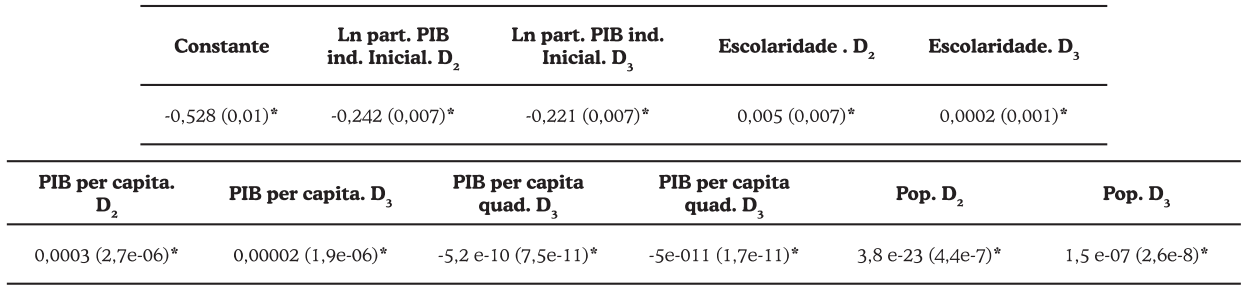

Fonte: Elaboração própria a partir dos resultados da pesquisa.

Nota: *Rejeita-se $\mathrm{H}_{0}$ a um nível de $5 \%$ (teste t). Entre parênteses refere-se ao desvio padrão do estimador. $\mathrm{D}_{2}$ assume " 1 " quando a microrregião é do grupo dois e "0" se contrário; $\mathrm{D}_{3}$ assume "1" quando a microrregião pertence ao grupo três e "0", se contrário. Ln refere-se ao logaritmo.

Ressalta-se que nessa hipótese está se relaxando a suposição de características estruturais comuns entre as microrregiões, considerando que as possíveis diferenças na participação do PIB industrial estejam sendo definidas pelas condições iniciais de cada microrregião. Os resultados obtidos apontaram para a grande importância tanto das condições iniciais quanto das características estruturais na determinação da participação no PIB industrial de cada microrregião, demonstrando existir múltiplos equilíbrios estáveis. Os diversos picos observados com relação aos coeficientes refletem exatamente essas diferenças estruturais entre as regiões estudadas.

Por exemplo, no caso do cluster 3 - o qual apresentava inicialmente os piores valores médios para as variáveis participação inicial no PIB industrial, PIB per capita, escolaridade (Tabela 4) -, a velocidade de convergência obtida foi menor (14,8\% a.a.) do que a do grupo dois (15,9\% a.a.), cujas características iniciais eram melhores. Cada um dos clubes exibe um modelo linear distinto dos demais, caracterizado internamente por microrregiões que possuem os mesmos parâmetros e as mesmas condições iniciais.

Tabela 4 - Valores médios das variáveis selecionadas em cada cluster: 1996 para as três primeiras variáveis e 1985 para a última

\begin{tabular}{cccccc}
\hline Cluster & $\begin{array}{c}\mathbf{N}^{\circ} \text { de } \\
\text { Microrregióes }\end{array}$ & $\begin{array}{c}\text { PIB per capita } \\
\text { (R\$) }\end{array}$ & $\begin{array}{c}\text { Escolaridade } \\
\text { média (anos) }\end{array}$ & $\begin{array}{c}\text { População } \\
\text { (habitantes) }\end{array}$ & $\begin{array}{c}\text { Participação inicial } \\
\text { no PIB industrial do } \\
\text { Sul do Brasil (\%) }\end{array}$ \\
\hline 1 & 2 & 11.398 & 8,0 & 2.668 .526 & 18,42 \\
2 & 26 & 8.191 & 7,3 & 319.374 & 1,66 \\
3 & 66 & 4.273 & 6,9 & 143.746 & 0,30 \\
\hline
\end{tabular}

Fonte: Elaboração própria a partir dos resultados da pesquisa.

Percebe-se, pelos dados da Tabela 3, que em todos os clusters as variáveis relevantes para explicar o crescimento na participação do PIB industrial, além da participação inicial no período, foram os anos médios de escolaridade, o PIB per capita e a população. Isso indica que investimentos em capital humano tendem a 
melhorar a estrutura produtiva da região, aumentando consequentemente a produtividade. Esse efeito tende a se dar num montante maior no cluster dois, o qual apresenta características iniciais melhores do que o três e que possivelmente por isso já tenha uma estrutura produtiva mais desenvolvida (em termos tecnológicos), mais apta para utilizar trabalhadores mais qualificados.

No caso da população, o seu efeito é significativamente maior no cluster três, sugerindo que o parque industrial existente nessas regiões é mais intensivo em mão de obra que no grupo dois. Por isso, o aumento da população tende a aumentar a oferta de trabalhadores, podendo se elevar a produção sem necessariamente ter acréscimos no valor pago pelos salários. No caso do PIB per capita, este veio com um efeito positivo inicialmente sobre a participação no PIB industrial, mas à medida que vai aumentando seu valor, sua influência passa a ser menor.

Portanto, as características estruturais - produtividade, padrão de consumo e mão de obra -, em conjunto com as condições iniciais de cada clube, influenciaram a participação de cada microrregião no PIB industrial da região Sul.

\section{Considerações Finais}

O objetivo deste estudo foi analisar a distribuição espacial do setor secundário na região Sul do Brasil e sua convergência, no período de 1985 a 2009. Para tanto, foi aplicado o método de análise regional, por meio da medida de localização QL e de estimativas em dados de painel, com o intuito de identificar a convergência industrial.

A comparação da distribuição das microrregiões especializadas do período de 1985 a 2009 demonstrou uma melhora, com todos os estados do Sul aumentando o percentual de microrregiões especializadas na indústria. Além disso, o número das microrregiões que apresentavam QL fraco e que passaram a ter um valor médio se elevou, indicando um avanço quanto ao potencial de especialização produtiva no conjunto da região. Nesse quesito, os resultados convergiram com outros estudos citados ao longo do texto, demonstrando certo consenso no reposicionamento de atividades produtivas de transformação ao longo do espaço do Sul.

Destaca-se, ainda, que no decorrer do período de análise, principalmente em Santa Catarina, a distribuição espacial das microrregiões especializadas no setor secundário ficou mais homogêneo, não estando localizadas apenas nos dois corredores e no aglomerado identificado em 1985. Essa desconcentração espacial se tornou importante para que possíveis transbordamentos industriais tragam, ex post, um crescimento industrial para todo o Sul do país. Essa tendência de convergência quanto à estrutura produtiva foi comprovada. Mais do que isso, não só se tem essa convergência como também os resultados apontam para a grande 
importância das condições iniciais e das características estruturais (escolaridade, população, PIB per capita) na determinação da participação no PIB industrial de cada microrregião, existindo múltiplos equilíbrios estáveis. Cabe ressaltar que a importância das condições estruturais a muito vem sendo discutida na literatura econômica. No caso do Sul, os resultados da pesquisa foram bem contundentes quanto a essas características e condições. Ou seja, o capital humano continua sendo o principal instrumento de fomento para a melhoria da produtividade e de ganhos de escala na estrutura produtiva.

Assim, em cada grupo identificado, o controle das variáveis estruturais, com sua fomentação, se torna importante para alavancar o crescimento industrial. Mas do que isso, conhecer as particularidades de cada grupo e considerá-las ao formular políticas públicas é indispensável para que se tenha, no futuro, uma região mais homogênea em termos de produção industrial. Porém, para isso, cabe pensar numa política específica de desenvolvimento regional para o Sul que congregue seus principais órgãos financiadores e de fomento (BRDE, CAIXARS, BESC, etc.) com os instrumentos e fóruns de descentralização de políticas públicas e de decisão regional. Apesar de cada estado do Sul apresentar uma estratégia diferenciada de política de descentralização e desenvolvimento regional, algumas discussões podem ser coletivas da mesma maneira que a estratégia. Pelos resultados da pesquisa apresentada neste texto, a discussão das características estruturais de cada estado e seu papel frente às políticas nacionais de desenvolvimento é um bom marco para o início de uma política de desenvolvimento regional comum no Sul do Brasil.

\section{Referências}

ALVES, Y. B.; FERRERA DE LIMA, J. A distribuição regional do emprego formal no Sul do Brasil. Textos de Economia, v. 11, n. 2, p. 15-30, 2008.

ANDRADE, M. C. De espaço, polarização e desenvolvimento: uma introdução à economia regional. São Paulo: Atlas, 1987.

BARRO, R.; SALA-I-MARTIN, X. Technological diffusion, convergence, and growth. Journal of Economic Growth, v. 2, n. 1, p. 1-26, 1995.

BERTUSSI, G.L.; FIGUEIREDO, L. 2009. Hipótese de Convergência: uma análise para a América Latina e o Leste Asiático entre 1960-2000. Texto para discussão n 354, UFMG/Cedeplar.

CANO, W. Concentração e desconcentração econômica regional no Brasil: 1970/95. Economia e Sociedade, Campinas, v. 6, n.8, p.101-141, jun. 1997.

CARATORI, P. M. Transformação estrutural: uma abordagem estatística para analisar o peso do setor industrial no produto. 2011. 39f. Dissertação (Mestrado em Finanças e Economia Empresarial). Fundação Getúlio Vargas, Rio de Janeiro, 2011.

DINIZ, C. C. A dinâmica regional recente da economia brasileira e suas perspectivas. Brasília: IPEA, 1995. (Texto para Discussão n. 375). 
FEIJÓ, C. A.; CARVALHO, P. G. M.; RODRIGUEZ; M. S. Concentração industrial e produtividade do trabalho na indústria de transformação nos anos 90: evidências empíricas. EconomiA, Niterói, RJ, v.4, n. 1, p. 19-52, jan./jun. 2003.

FERRERA DE LIMA, J. La concentration spatiale des activités productives au Bresil. Organisations 8 Territoires, Chicoutimi, Canada, v. 21, n. 2, p. 39-45, 2012.

. La diffusion spatiale du développement économique regional. Sarrabruck: Éditions Universitaires Europpéennes, 2010.

FERRERA DE LIMA, J. et al. O padrão de localização e de difusão da mão de obra na região Sul do Brasil (1991-00). Ensaios FEE, Porto Alegre, v. 28, n. 1, p. 189-224, 2007.

FIRKOWSKI, O. L. C. F. Industrialização, questão ambiental e Mercosul. Geografia, Londrina, v. 8, n. 2, p. 161-174, 1999.

GALOR, O.; ZEIRA, J. Income distribution and macroeconomics. Review of Economic Studies, v. 60, n. 1, p. 35-52, 1993.

GRUBER, R.; CAMPOS, S. M.; FERRERA DE LIMA, J. O mercado de trabalho nas cidades médias da região Sul do Brasil: aplicação do Índice de Saboia. Ensaios FEE, v. 30, n. 1, p. 135-164, 2009.

HADDAD, P. R. Medidas de localização e de especialização. In: HADDAD, P. R. (Org.). Economia regional: teorias e métodos de análise. Fortaleza: BNB/ETENE, 1989. p. 225-248.

HIRSCHMAN, A. Estratégia do desenvolvimento econômico. São Paulo: Fundo de Cultura, 1961.

INSTITUTO BRASILEIRO DE GEOGRAFIA E ESTATISTICA. Estados: Paraná. Rio de Janeiro, 2013. Disponível em: < http://www.ibge.gov.br/estadosat/perfil.php?sigla=pr $>$. Acesso em: 3 out. 2012.

. Estados: Rio Grande do Sul. Rio de Janeiro, 2013. Disponível em: < http://www.ibge.

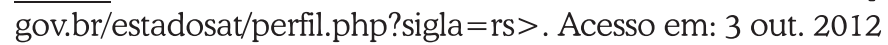

. Estados: Santa Catarina. Disponível em: http://www.ibge.gov.br/estadosat/perfil. php?sigla $=$ sc. Acesso em 3 out. 2012

INSTITUTO DE PESQUISA ECONÔMICA APLICADA. Caracterização e tendências da rede urbana do Brasil: configurações atuais e tendência da rede urbana. Brasília, v. 1, 2001.

IPEADATA. Regional. Disponível em: <http://www.ipeadata.gov.br>. Acesso em: 3 out. 2012.

KALDOR, N. The case for regional policies. In: TARGETTI, F.; THIRWWALL, A. The essential Kaldor. New York: Holmes E Meier, p. 311-326, 1989.

KLEINSCHMITT, S. C.; FERRERA DE LIMA, J. Polarização e dispersão industrial nas microrregiões do Sul do Brasil. Revista Geografar, v. 6, n. 1, p. 55-75, 2011.

MARTINE, G.; DINIZ, C. C. Concentração econômica e demográfica no Brasil: recente inversão do padrão histórico. Revista de Economia Política, São Paulo, v. 11, n. 3, p. 121-135, jul./set. 1991.

PERROUX, F. O conceito de polo de crescimento. In: FAISSOL, S. Urbanização e regionalização: relações com o desenvolvimento econômico. Rio de Janeiro: IBGE, 1974. p. 97-110. 
PIEPER, U. Deindustrialization and the social and economic sustainability nexus in developing countries: cross-country evidence on productivity and employment. Center for Economic Policy Analysis, 1998. (Working Paper).

PINHEIRO, M. C. Evolução regional e convergência da produtividade da mão de obra industrial brasileira (1960-1995). 2001. 81f. Dissertação (Mestrado em Economia). Fundação Getúlio Vargas, Rio de Janeiro, 2001.

SINGER, P. População e desenvolvimento econômico. São Paulo: Hucitec, 1971.

SOUZA, E. L. C.; FERRERA DE LIMA, J. A desconcentração industrial na região Sul do Brasil. Revista de Economia Mackenzie, v. 8, n. 1, p. 04-25, 2010.

SOUZA, N. J.; PORTO JÚNIOR, S. S. Crescimento regional e novos testes de convergência para os municípios da região Nordeste do Brasil. Encontro Brasileiro de Estudos Regionais e Urbanos, São Paulo, 2002.

THIRLWALL, A. P. A natureza do crescimento econômico: um referencial alternativo para compreender o desempenho das nações. Brasília: IPEA, 2005.

WOOLDRIDGE, J. M. Econometric analysis of cross-section and panel data. Boston: Massachussetts Institute of Technology, 2002. 
Apêndice A - Dendograma de Variáveis Selecionadas para as Microrregiões do Sul do Brasil (1985-1996)

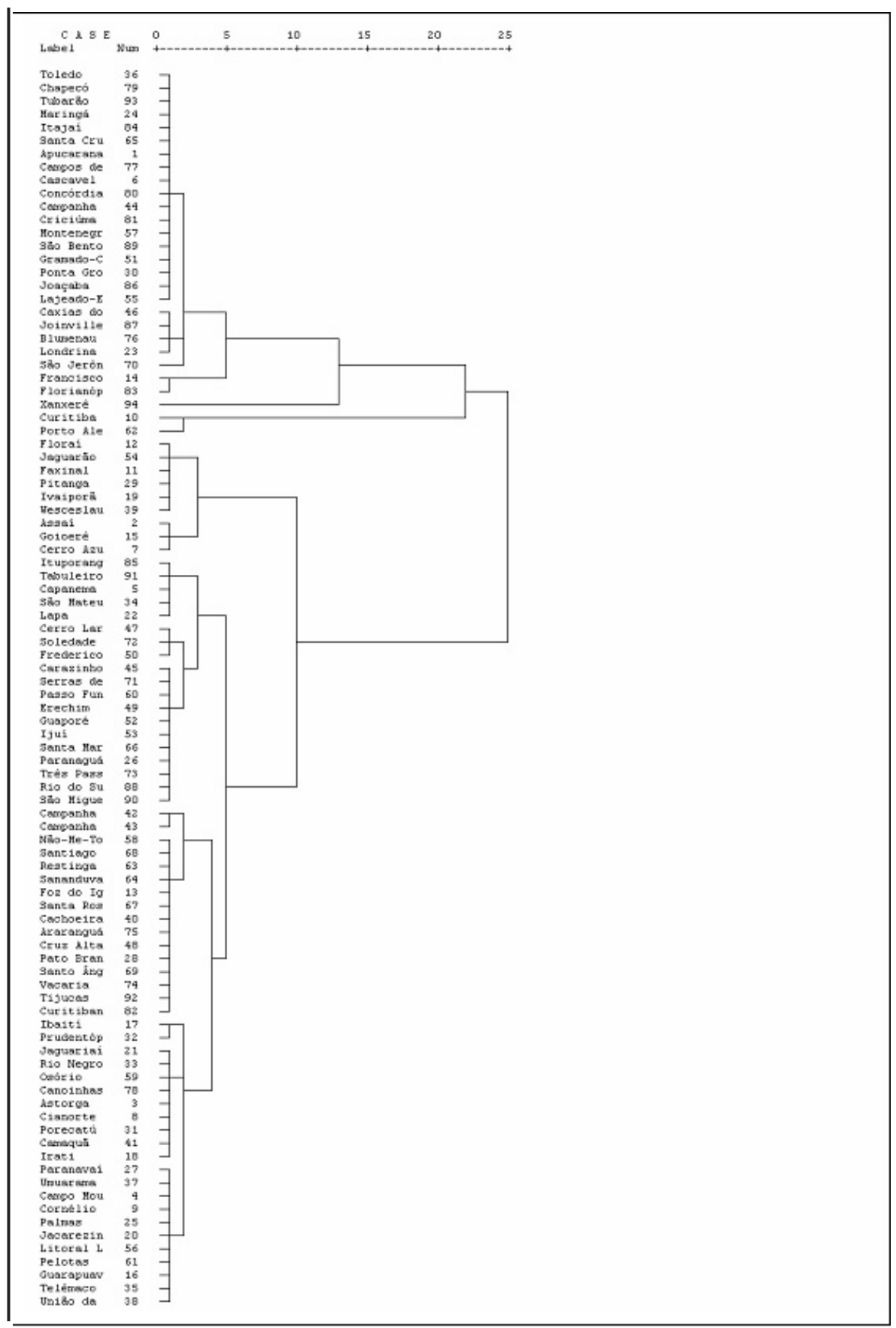

Fonte: Elaboração própria a partir dos resultados da pesquisa.

RAIHER, A. P.; FERRERA DE LIMA, J.; KLEIN, C. F. A Distribuição Espacial da Indústria... 


\section{Apêndice B - Testes Econométricos das Regressões}

\begin{tabular}{lcccc}
\hline \multicolumn{1}{c}{ Convergência } & $\begin{array}{c}\text { Heterocedasticidade (teste } \\
\text { modificado de Wald) }\end{array}$ & $\begin{array}{c}\text { Autocorrelação } \\
\text { (Woodridge) }\end{array}$ & Hausman \\
\hline Absoluta - Sul do Brasil & $2,6 \mathrm{e}+05^{*}$ & $138^{*}$ & $527^{*}$ \\
Absoluta - Paraná & $32065^{*}$ & $74^{*}$ & $229^{*}$ \\
Absoluta - Santa Catarina & $1,4 \mathrm{e}+05^{*}$ & $83^{*}$ & $111^{*}$ \\
Absoluta - Rio Grande do Sul & $2795^{*}$ & $47^{*}$ & $185^{*}$ \\
Condicional - Sul do Brasil & $2,1 \mathrm{e}+05^{*}$ & $78^{*}$ & $119^{*}$ \\
Condicional - Paraná & $1533^{*}$ & $33^{*}$ & $127^{*}$ \\
Condicional - Santa Catarina & $4758^{*}$ & $24^{*}$ & $191^{*}$ \\
Condicional - Rio Grande do Sul & $2,2 \mathrm{e}+05^{*}$ & $65^{*}$ & $390^{*}$ \\
Clube de convergência & $2,4 \mathrm{e}+07^{*}$ & $29^{*}$ & $24^{*}$ \\
\hline condicional & &
\end{tabular}

Fonte: Elaboração própria a partir dos resultados da pesquisa.

Nota: ${ }^{*}$ Rejeita $\mathrm{H}_{0}$.

Recebido em: 14/03/2013.

Aceito em: 02/08/2013. 